\title{
Experimental Research on the Dynamic Response of Floating Structures with Coatings Subjected to Underwater Explosion
}

\author{
Feng Xiao, ${ }^{1}$ Yong Chen, ${ }^{1}$ Yu Wang, ${ }^{2}$ Hongxing Hua, ${ }^{1}$ and Dawei Zhu ${ }^{1}$ \\ ${ }^{1}$ Institute of Vibration, Shock \& Noise, State Key Laboratory of Mechanical System and Vibration, School of Mechanical Engineering, \\ Shanghai Jiao Tong University, 800 Dong Chuan Road, Minhang District, Shanghai 200240, China \\ ${ }^{2}$ Naval Research Center, Liuliqiao Road, Fengtai District, Box 1303-14, Beijing 100073, China
}

Correspondence should be addressed to Feng Xiao; xiaofengsjtu@yahoo.com.cn

Received 16 May 2013; Accepted 2 September 2013; Published 27 March 2014

Academic Editor: Vadim V. Silberschmidt

Copyright ( $\odot 2014$ Feng Xiao et al. This is an open access article distributed under the Creative Commons Attribution License, which permits unrestricted use, distribution, and reproduction in any medium, provided the original work is properly cited.

\begin{abstract}
This paper presents an experimental investigation into the dynamic response of three free floating stiffened metal boxes with protective coatings subjected to underwater explosion (UNDEX). One box was kept intact while the other two were, respectively, covered with monolithic coatings and chiral honeycomb coatings. Three groups of live fire tests with different attack angles and stand-off distances were conducted. The acceleration on the stiffener and strain peak on the bottom hull were selected as the major comparative criterions. Test results show that the impulse transmitted to the structure at the initial stage can be reduced, owing to the coating flexibility and fluid-structure interaction mechanism. Consequently, the acceleration peaks induced by both shock wave and bubble pulse were reduced. The shock environment can be more effectively improved by honeycomb coating when compared with monolithic coating. Most of the strain peaks decreased to a certain extent, but some of them were notably manifested, especially for honeycomb coating. The test affirms the fact that soft coating can cause stress concentration on the shell that is in direct contact with the coating due to the impedance mismatch between the interfaces of materials. A softer rubber coating induces a greater magnitude of strain.
\end{abstract}

\section{Introduction}

In naval warfare, warship and submarine will inevitably suffer from underwater explosions. Unlike contact explosion, noncontact explosion does not break ship's hull, but shock wave and bubble pulse usually cause great impact to ship and result in the permanent deformation of hull plate, breakdown of onboard equipment and casualty of personnel.

How to moderate the devastating damage is very important and of great interest to ship designers. Many efforts have been taken to enhance the warship's blast resistance since World War I (WWI). Early measures include reinforcing the hull and building the multilayer hull, but very complex engineering constructions are needed and big volumes are occupied. Such inconvenience prevents a further use of these techniques in modern ships [1]. Furthermore, existing devices and units mounted on the ship cannot meet the needs of good shock and vibration isolation at the same time [2]. Moreover, these units cannot reduce the total shock wave energy transmitted to ship. In 1990s, US navy [3] studied the shock resistance of a ship covered with protective coating. Research at the Naval Postgraduate School continues in an effort to understand the dynamic response of coated structures subjected to shock waves. The coating is a shock protective layer that can be plastered onto the ship hull's wet surface in resistance to noncontact underwater explosion. It is stable under normal water pressure but very flexible under high shock loading. The working mechanism is mainly based on the energy absorption of coating through large deformation with a very short time interval as well as the wave reflection between the interfaces of materials with great acoustic impedance mismatch. Elastomers or viscoelastic rubbers are often used owing to their low modulus, high damping, large extensibility, recoverable deformation, low costs, and short cycle for repairing. Simple building technique merit makes it become a good choice at least when applied to weak or medium shock environment. In particular, nowadays special cavities are set in the coating for acoustic functions. 
Sandwich structures are widely used in engineering fields, especially in marine environment. Sandwich plates and beams have higher shock resistance than monolithic counterpart of equal mass under shock loading in both air and water [4-13]. Based on these results, sandwich coating has drawn much attention to the blast protection of ship subjected to noncontact underwater explosion. Chen et al. $[14,15]$ explored the attenuating effects of sandwich coating with square core coated onto the scaled ship model subjected to water blasts. Experimental results showed that soft core substantially reduce the transmitted impulse and the structure shock responses induced by the first shock wave can be lowered greatly after the polymer layer is coated. Elastic protective coating technique with soft core can be applied to weak or medium shock environment.

Meanwhile, the influence of soft coating on the shock response of submerged structures is concerned. Permanent structure deformation may be undesirable if the structure is to be used even after the blast. Rubber coatings appear to concentrate shock energy within the structure for longer time periods. The study conducted by US Navy [3] revealed that if a steel panel was covered with a low density layer of glass microspheres, the damage to the steel panel caused by underwater explosion would increase. The thickness, shear deformation modulus, and sound impedance of coating had a large effect on structure stress. Kwon et al. [16] numerically studied the effect of coatings on metal cylinders in the underwater explosion environment. The results showed that the coating can concentrate shock energy within the structure under certain impact conditions. In a particular application, the occurrence of energy concentration is determined by a threshold value, below which adverse dynamic responses of a coated cylinder will occur. Additional research by Brasek [17] about one-dimensional system has demonstrated that the threshold value may depend upon the geometry and material properties of both coating and structures. Experimental research by Chen et al. [18] on the response of neoprene coated cylinder subjected to underwater explosions showed that, after the rubber layer is coated, the strain on the outer hull is notably manifested, especially in the hoop direction. However, no effect of stress concentration on the hull was observed in the research on the protective effect of a sandwich layer coated on ship hull [14].

Considering the fact that some periodic honeycomb structures have good energy absorption capability and acoustic insulation property, which is very helpful for the acoustic stealth of ship, honeycomb rubber coatings are proposed. To date, most researches about honeycomb structures concentrate upon metallic material and studies on the dynamic response of honeycomb rubber coatings have been very limited. A comparative investigation on the water blast attenuation performance and stress concentration of the submerged structures covered with solid rubber coating and honeycomb rubber coating has not been conducted. Further, the influence of attack angle is also not considered. The dynamic response of a structure subjected to underwater explosion is a very complicated problem due to the interaction between fluid and structure. The outermost hull of a ship comprises plates welded to an array of stiffeners and the water blast response of plate structure is the basis of warship's blast resistance $[19,20]$. This paper presents an experimental investigation on the water blast responses of a free floating stiffened box before and after coatings are covered onto its bottom hull with different attack angles and stand-off distances. The principal aim of the paper is to explore the advantages and disadvantages of honeycomb coating relative to solid coating of the same material and weight in terms of the attenuation effect of coatings and the stress concentration on the hull. The main outline of this paper is as follows. First, the stiffened metal box and coatings are introduced. Second, the relevant material characteristics and quasistatic compression performance of coatings are presented. Third, the experimental procedures are detailed, including both test method and measuring instruments. The free field water pressure, wall pressure, acceleration in the time domain and frequency domain, and strain are compared. Last, an overall conclusion is made.

\section{Experimental Research}

Many other methods such as impact test can be used to study the performance of coating, but live UNDEX test is the most authentic way to evaluate the actual effect of the coating as the transient response of the hull with rubber coating subjected to underwater explosion is a very complex process, such as shock wave incidence and reflection, large deformation, hull motion, and strain and strain rate dependent behavior.

2.1. Target Models. Three stiffened metal boxes of the same geometry were manufactured. For convenience, we name the box without coatings model I and name the box with monolithic solid coatings model II and name the box with chiral honeycomb coatings model III. The total mass of model I is about $300 \mathrm{~kg}$ and the mass of all coatings is $76 \mathrm{~kg}$. The weight of monolithic coatings is the same as that of honeycomb coatings. The global dimensions of the stiffened metal box are $1.5 \mathrm{~m} \times 1.2 \mathrm{~m} \times 0.4 \mathrm{~m}$, as shown in Figure 1(a). Four side plates were welded at the bottom ends for a waterproof. The bottom and side plates were reinforced by three longitudinal stiffeners and four transverse stiffeners. The stiffeners are $0.075 \mathrm{~m}$ high. The spacing of the longitudinal stiffeners is $0.3 \mathrm{~m}$ and the spacing of the transverse stiffeners is $0.4 \mathrm{~m}$. All the plates and stiffeners were made by $0.004 \mathrm{~m}$ thick steel plate except the side plates which are $0.02 \mathrm{~m}$ thick. The model was designed to be simple but strong enough to withstand the shock wave. The material used is common mild steel $A 4$, with the yielding stress beyond $250 \mathrm{MPa}$. Altogether 97 pieces of the coatings were plastered onto the outer surface of bottom hull with epoxy resin glue piece by piece, as shown in Figure 1(b). The gaps between different pieces were filled and leveled up with asphalt. The sooty part indicated by the arrowhead is the coating. The practical shape and detailed dimension of a single honeycomb coating are shown in Figure 2. Its global dimensions are $200 \mathrm{~mm} \times 50 \mathrm{~mm} \times 95 \mathrm{~mm}$. The coating is $50 \mathrm{~mm}$ thick. Honeycomb cavities cover $20.7 \%$ of the whole volume. The plane of the honeycomb shown in Figure 2(b) is perpendicular to the plane of the hull. 


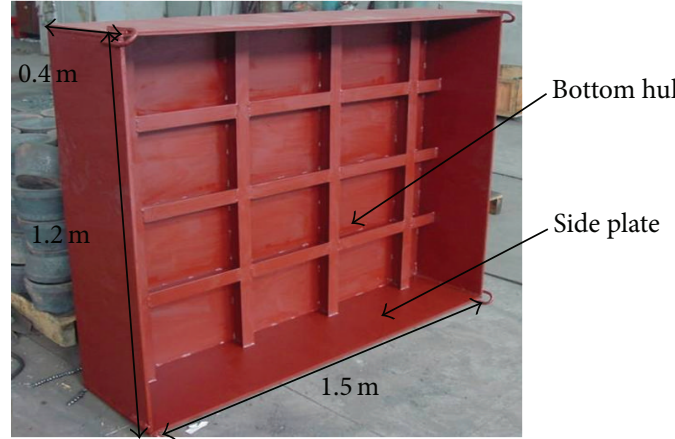

(a)

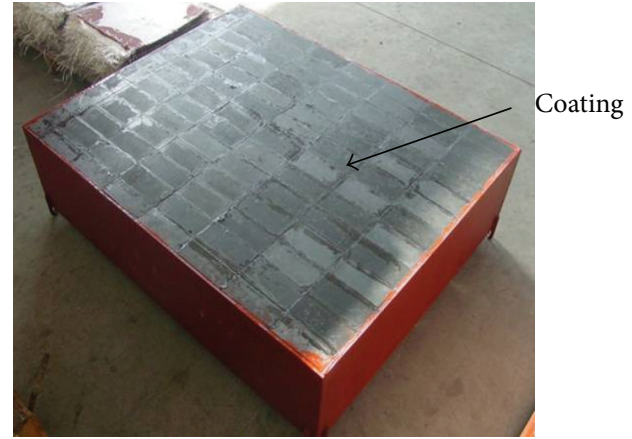

(b)

FIGURE 1: Test model of the stiffened box: (a) stiffened box without coatings, (b) stiffened box with coatings.

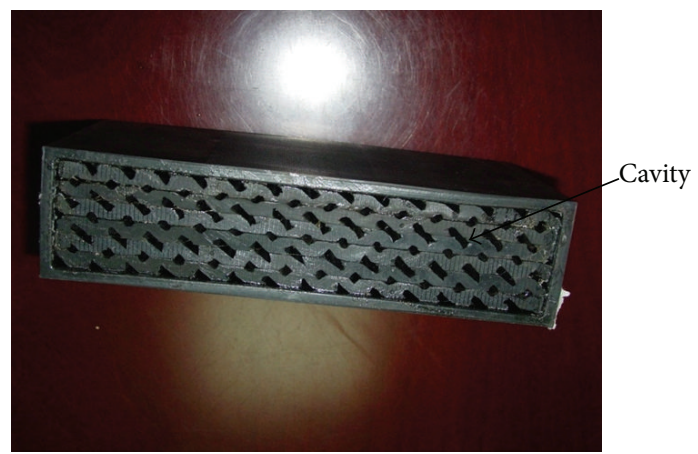

(a)

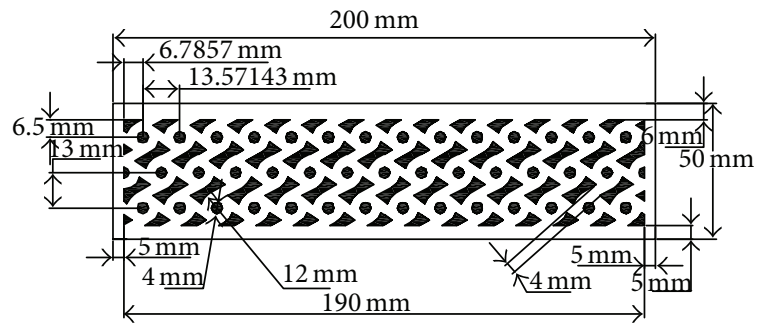

(b)

FIGURE 2: Chiral honeycomb coating: (a) geometry, (b) dimension.

TABLE 1: Material properties.

\begin{tabular}{lcccc}
\hline & Water & Neoprene & Air & Steel \\
\hline$\rho \cdot c\left(\mathrm{~kg} \cdot \mathrm{m}^{-2} \cdot \mathrm{s}^{-1}\right)$ & 1400000 & 224720 & 438.6 & 40472212 \\
$C(\mathrm{~m} / \mathrm{s})$ & 1400 & 212 & 340 & 5188 \\
\hline
\end{tabular}

2.2. Mechanical Property of the Coating. The basic material used in the study is neoprene $[15,21]$. The neoprene is a kind of synthetic rubber with sound flexibility and wearability that is produced by polymerization of chloroprene. In order to characterize the material with different levels of hardness, some specimens were tested on an INSTRON universal material testing machine. For the restriction of conditions, the biaxial and volumetric test data were unavailable. Figure 3 shows the stress-strain curves of three kinds of neoprene with different levels of hardness. Both tensile and compressive behaviors were included. The materials exhibit excellent flexibility as the specimen can be elongated up to $300 \%$ without any visible damage. The difference in compressive stress of three kinds of neoprene increases with the strain and their tensile stress is similar. Considering coating's bearing capacity and long service life, the neoprene with shore hardness number 65 is used.

Material properties are listed in Table 1. Acoustic speed can be estimated as $C=\sqrt{E / \rho}$, where $E$ is the modulus and $\rho$ is the density. $\rho \cdot c$ is the acoustic wave impedance. The acoustic impedance of neoprene and air are much smaller and the wave speed is lower than that of common steel. When the blast wave reaches the interface, reflection and transmission occur. As cavities are air filled, the acoustic impedance of honeycomb coating is greatly changed. Therefore, there exist great impedance mismatches in the transmission of waves.

In addition to the mechanical property of base material, knowledge about the dynamic compression behavior of coatings facilitates the comprehension on its performance in underwater explosion environment. A whole piece of coating is so large that it is very difficult to test directly on common material test machines. As a substitution, a small piece of coating is cut from the box after live fire tests have been finished. The dimensions of the cut specimen are $200 \mathrm{~mm}$ $\times 200 \mathrm{~mm}$. The uniaxial compression test was performed on a $100 \mathrm{KN}$ Zwick general material test machine. During tests, the specimen was clamped between two thick circular plates. Only quasistatic compression test was performed. The quasistatic compression velocity was selected as $10 \mathrm{~mm} / \mathrm{min}$ and applied to the coating's upper surface in Figure 2(b). Figure 4 shows the comparison of the stress-strain curves of monolithic coating and honeycomb coating. The nominal stress of the structure is defined as the measured force divided by the cross-sectional area of samples. The nominal strain of the structure is the crushing distance divided by the initial 


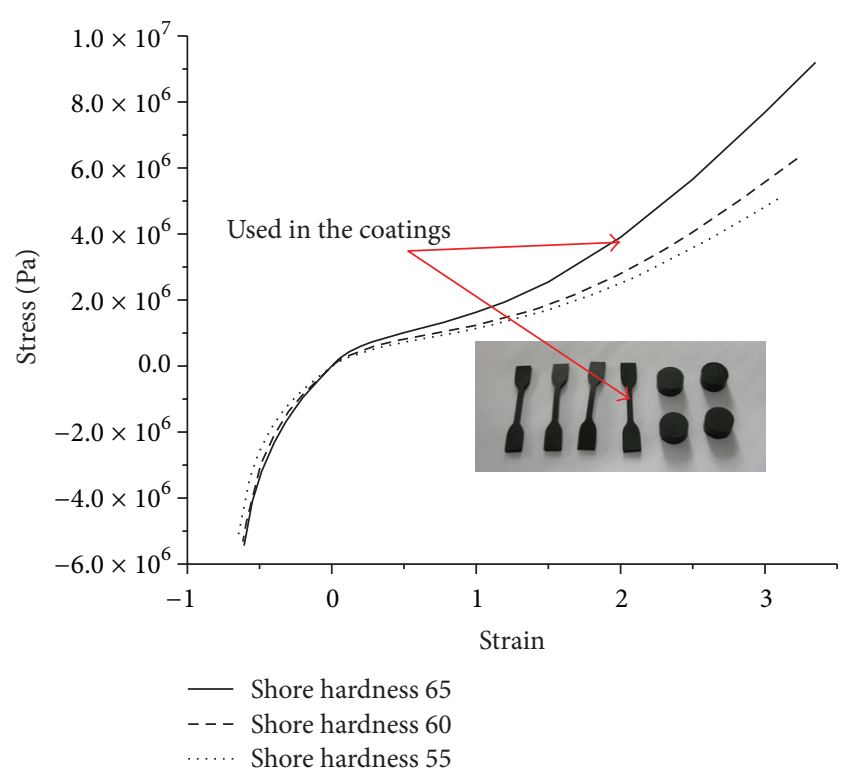

FIGURE 3: Stress-strain curve of the neoprene with different shore hardness.

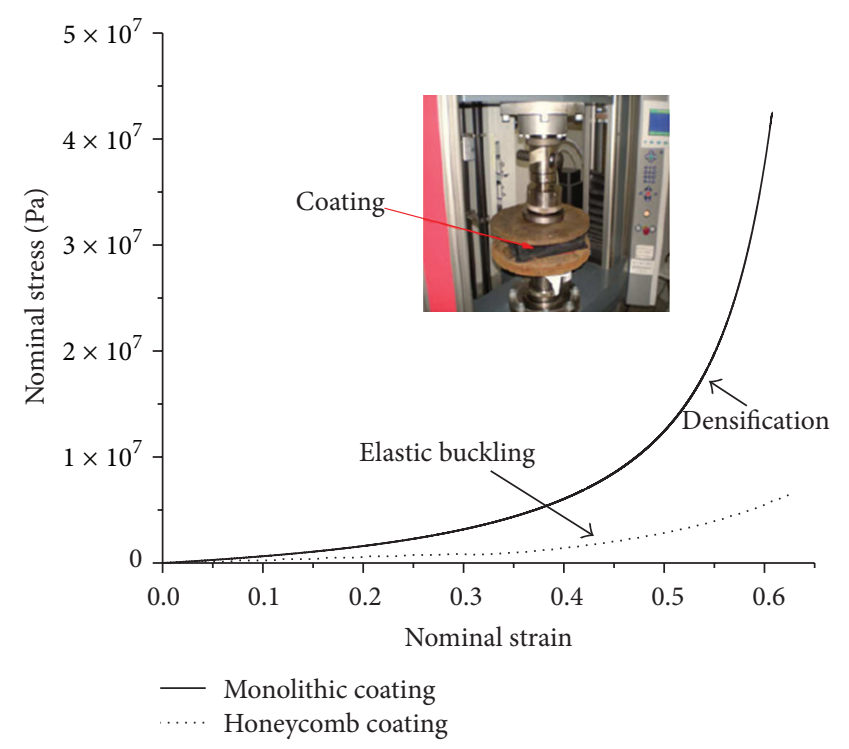

FIGURE 4: Stress-strain curves of monolithic coating and honeycomb coating.

thickness of samples. It can be seen that honeycomb coating has much larger compressibility than monolithic one. There is not a high initial peak on the curves. The stress of monolithic coating is higher and the densification takes place much earlier with the structural stiffness when compared with that of honeycomb coating. When the honeycomb coating is loaded, the energy is absorbed by cell buckling. Soft coating decreases the level of stress at the expense of total compression distance. Under the same compression distance, honeycomb coating absorbs less energy. As a result, it is easy to deform.

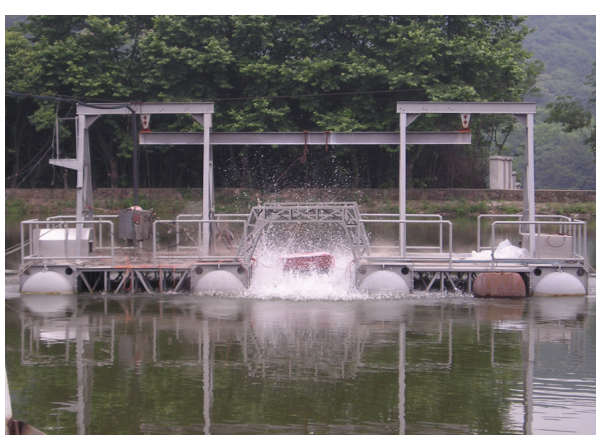

Figure 5: Underwater explosion test.

TABLE 2: Test events.

\begin{tabular}{lcccccc}
\hline $\begin{array}{l}\text { Test event } \\
\text { number }\end{array}$ & Model & $W(\mathrm{~kg})$ & $R(\mathrm{~m})$ & $L_{1}(\mathrm{~m})$ & $\beta\left(^{\circ}\right)$ & $\mathrm{SF}$ \\
\hline 1 & I & 1 & 4.39 & 7.00 & 30 & 0.12 \\
2 & II & 1 & 4.39 & 7.00 & 30 & 0.12 \\
3 & III & 1 & 4.39 & 7.00 & 30 & 0.12 \\
4 & I & 1 & 2.83 & 4.30 & 30 & 0.18 \\
5 & II & 1 & 2.83 & 4.30 & 30 & 0.18 \\
6 & III & 1 & 2.83 & 4.30 & 30 & 0.18 \\
7 & I & 1 & 7.50 & -0.60 & 90 & 0.14 \\
8 & II & 1 & 7.50 & -0.60 & 90 & 0.14 \\
9 & III & 1 & 7.50 & -0.60 & 90 & 0.14 \\
\hline
\end{tabular}

\subsection{Underwater Explosion Test}

2.3.1. Test Event. All tests were conducted in China Ship Scientific Research Center. A semispherical lake is 15 meters in depth and 80 meters in diameter, as shown in Figure 5. The test model was freely located in the middle of two interconnected floating platforms, which were supported by two buoyancy tanks and used to place instruments. Figure 6 shows the sketch of test system. $D 1$ is the waterline depth of about $0.2 \mathrm{~m} . R$ is the stand-off distance between the explosive charge and the center of bottom surface. $\beta$ is the attack angle. $L 2$ is the distance between the explosive charge and the free field water pressure transducer $(P 2)$. The shock factor representing the shock energy is defined as $S F=\sqrt{W} / R$ [22]. The SF varies from 0.12 to 0.18 . We chose to fix the explosive charge weight $(W)$ and vary the loading intensity by the change of the stand-off distance and attack angle. All test events were listed in Table 2. Nine events were attempted, including three predetermined stand-off distances $(4.39 \mathrm{~m}$, $2.83 \mathrm{~m}$, and $7.5 \mathrm{~m})$ and two attack angles $\left(30^{\circ}, 90^{\circ}\right)$. As long as equal blast loadings are guaranteed, assessments can be made. The charge weight in all events is $1 \mathrm{~kg}$. Before normal tests, a trial explosion was done in advance to examine the instruments.

2.3.2. Test Position and Instrumentation. As indicated in Figure 6, one wall pressure transducer $(P 1)$ to explore the fluid-structure interaction as well as the wave reflection characteristics with different targets is placed about $5 \mathrm{~mm}$ 


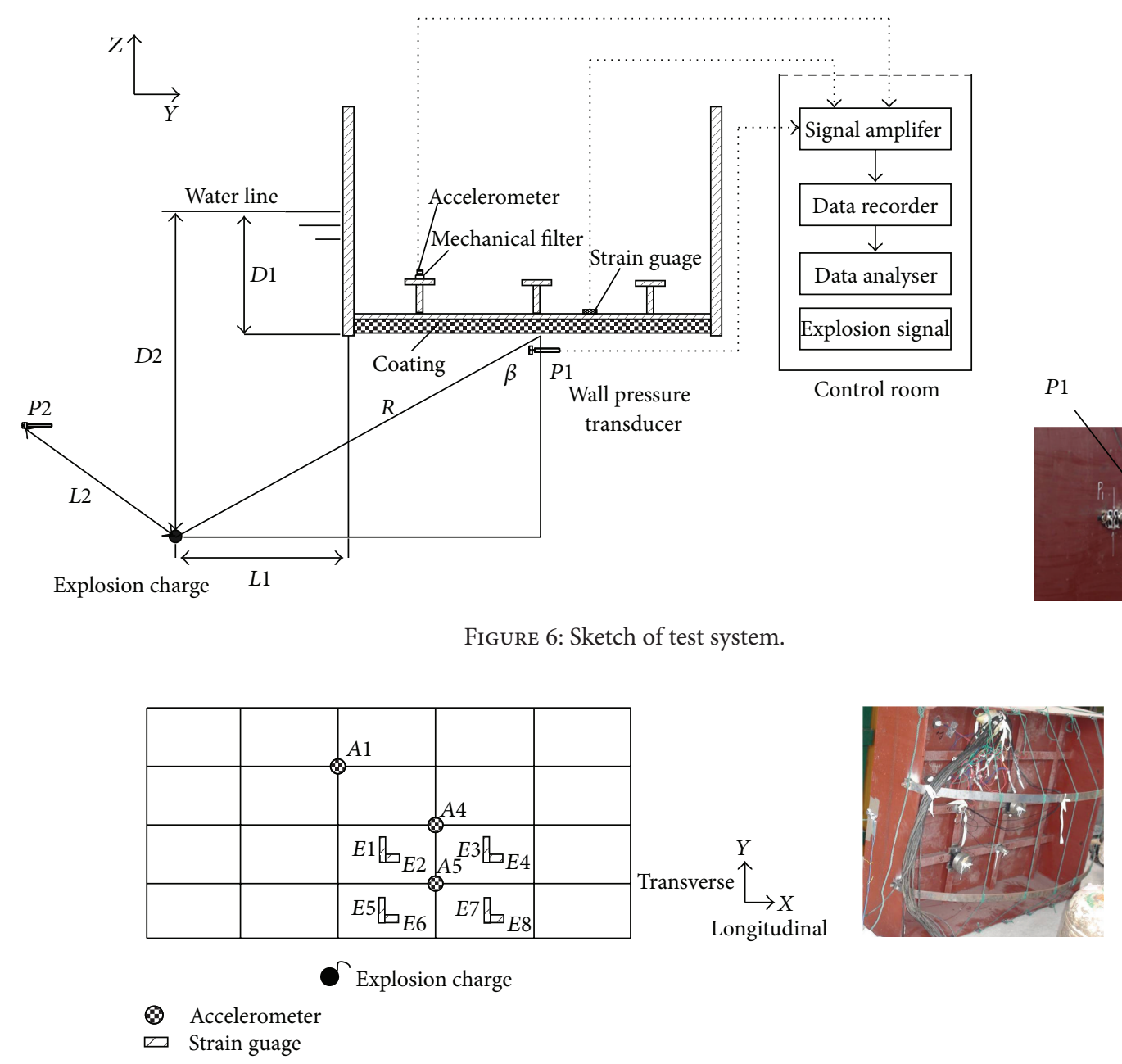

FIGURE 7: Locations of accelerometer and strain gauges.

vertically distant from the center of the bottom hull. One free field water pressure transducer $(P 2)$ to distinguish blast loads is suspended at the water depth of $4 \mathrm{~m}$. Figure 7 depicts the test positions, viewed from the bottom. Three accelerometers on the stiffeners and eight strain gauges on the inner bottom hull were used. All accelerometers were to measure the positive acceleration towards the sky. E1,E3, E5, and $E 7$ are the transverse gauges. $E 2, E 4, E 6$, and $E 8$ are the longitudinal gauges.

The instrumentation included transducers, preamplifiers, a data recording system, and some auxiliary devices. Two PCB 138A05 pressure transducers with linearity within $2 \%$ and range up to $35 \mathrm{MPa}$ were used to monitor water pressure. The accelerometers used are B\&K 4393 piezoelectric accelerometers that have a maximum operational shock range of $\pm 25000 \mathrm{~g}$, with upper frequency limit $16.5 \mathrm{kHz}$. In order to avoid overloading, all accelerometers are fixed at aluminum adaptors that are used as mechanical filters, with cut-off frequency around $3 \mathrm{KHz}$. Strain responses were tested with eight strain meters and manifested with a DC amplifier (DH3842). All gauges are of resistance style, with $350 \mathrm{ohm}$ resistance. A suit of 32-channel Odyssey high speed data recording device is used to record all electrical signals after detonation of the explosive. The pressure data are recorded with a maximum sampling frequency of $5 \mathrm{MHz} / \mathrm{Ch}$ (channel). The selected sampling rate is $50 \mathrm{KHz} / \mathrm{Ch}$ and $20 \mathrm{KHz} / \mathrm{Ch}$ for acceleration and strain records, respectively. The TNT (trinitrotoluene) is fabricated in the shape of a right cylinder formed by pressing it into a hollow tube constructed from PMMA (polymethyl methacrylate) and initiated with an exploding bridge wire detonator. The explosive device is fixed by the nylon cords that are fastened on the platforms. By adjusting the length of the cords, the explosive can be fixed at a scheduled position.

\section{Results and Discussions}

\subsection{Pressure Records}

3.1.1. Free Field Pressure-Time Profiles. Figure 8 shows the typical free field water pressure-time history of $P 2$ (event 1 ). The initial shock wave within $4 \mathrm{~ms}$ is magnified. It is seen that the pressure rises to a peak instantaneously upon the arrival of primary shock wave. Subsequently, it decreases at a nearly exponential rate. The reflected wave from the structure can 


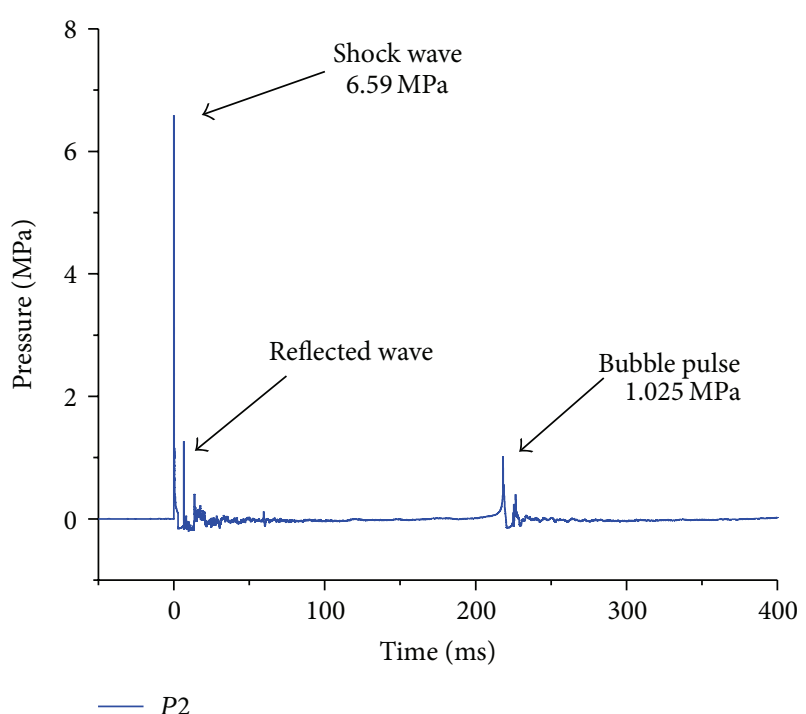

(a)

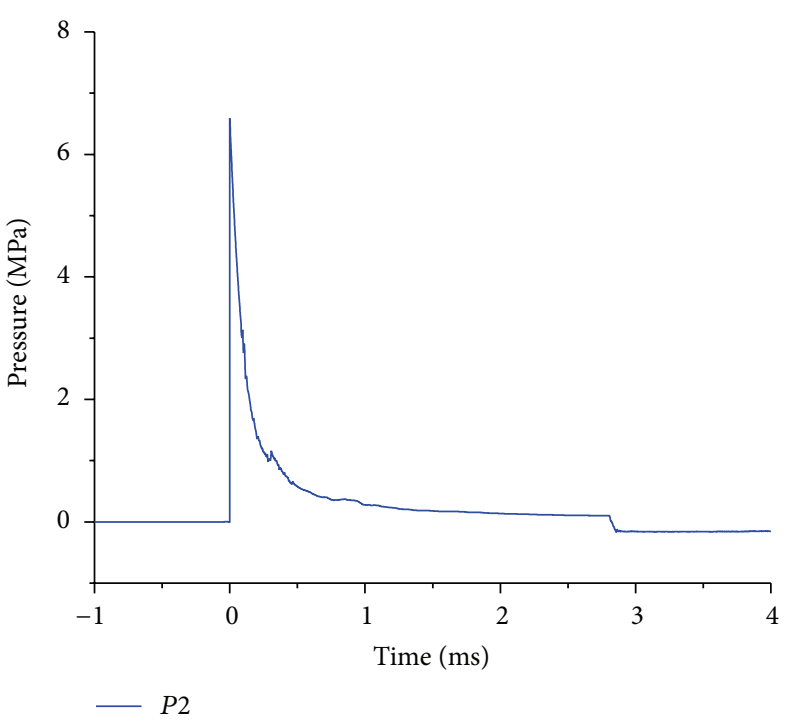

(b)

FIGURE 8: Free field water pressure-time history (event 1): (a) record within $400 \mathrm{~ms}$, (b) shock wave within $4 \mathrm{~ms}$.

TABLE 3: Summary of free field water pressure, wall pressure, and impulse.

\begin{tabular}{|c|c|c|c|c|c|c|c|}
\hline Event number & Model & $L_{2}(\mathrm{~m})$ & Theoretical peak (MPa) & Test peak (MPa) & Deviation (\%) & Wall pressure peak $(\mathrm{MPa})$ & Impulse $(\mathrm{Pa} * \mathrm{~s})$ \\
\hline 1 & I & 6.2 & 6.63 & 6.59 & -0.60 & 3.20 & 117.6 \\
\hline 2 & II & 6.2 & 6.69 & 6.33 & -5.3 & 2.16 & 59.4 \\
\hline 3 & III & 6.9 & 5.91 & 5.79 & -2.0 & 2.22 & 52.6 \\
\hline 4 & $\mathrm{I}$ & 3.6 & 12.22 & 12.02 & -1.6 & 8.12 & 215 \\
\hline 5 & II & 3.7 & 12.02 & 11.9 & -1.0 & 5.53 & 204 \\
\hline 6 & III & 6.1 & 6.79 & 6.89 & 1.5 & 5.13 & 118 \\
\hline 7 & I & 3.9 & 11.38 & 11.59 & 1.8 & 6.14 & 293.8 \\
\hline 8 & II & 3.8 & 11.63 & 11.69 & -0.60 & 6.31 & 269.3 \\
\hline 9 & III & 4.0 & 10.96 & 11.1 & 1.3 & 4.45 & 117.8 \\
\hline
\end{tabular}

also be distinguished, arriving at $6.53 \mathrm{~ms}$ after the shock wave passes. The secondary shock is subsequently experienced, due to the damped oscillation of the gas bubble that contains explosive products. The pressure peak of the shock wave is much higher and its duration is shorter compared with that of the bubble pulsation. The incident shock wave arrives instantaneously with a peak of $6.59 \mathrm{MPa}$ and then decays rapidly within about $0.4 \mathrm{~ms}$. The first bubble pulsation arrives at $218 \mathrm{~ms}$, with a broader profile and a low peak of $1.025 \mathrm{MPa}$. The bubble pulse pressure peak is $15.5 \%$ of the shock wave peak.

Accurate shock pressure loading is important. Table 3 lists all the free field pressure peaks in the shock wave phase. Considering the broad profile characteristics of bubble pulse, no comparison of their peaks is made. The free field theoretical peaks were obtained by Cole's empirical formula $P_{m}=52.4\left(W^{1 / 3} / R\right)^{1.13}[23]$. As stand-off changes from $2.83 \mathrm{~m}$ to $7.5 \mathrm{~m}$, the free field test peak increases from $5.79 \mathrm{MPa}$ to $12.02 \mathrm{MPa}$. The deviations between the theoretical peak and the test peak range from $0.6 \%$ (event 1 and event 8 ) to $5.3 \%$ (event 2). The deviation is within $5.5 \%$, which indicates that the explosion processes guarantee the following comparisons are authentic.

3.1.2. Wall Pressure-Time Profiles. The wall pressure-time profiles are very helpful in understanding the working mechanism of the coating. The wall pressure is the result of blast wave, divergent rarefaction wave, and reflected wave. Figure 9 presents the comparison of the wall pressure-time histories. Several distinct phases can be observed, including incidence, reflection, and cavitation. The whole process begins with the direct shock wave from the explosive, which is immediately followed by the reflected wave and later a tension wave produced by the onset of the cavitation near the bottom hull. As the face sheet moves, the fluid-structure interaction changes and the reflection is significantly reduced. The subsequent broad pressure wave indicates the repeating elastic deformation of the hull.

In Figure 9(a), the first incident wave peaks of coated models are much smaller than that of uncoated model as listed in Table 3. The reflected wave of model II is obvious. 


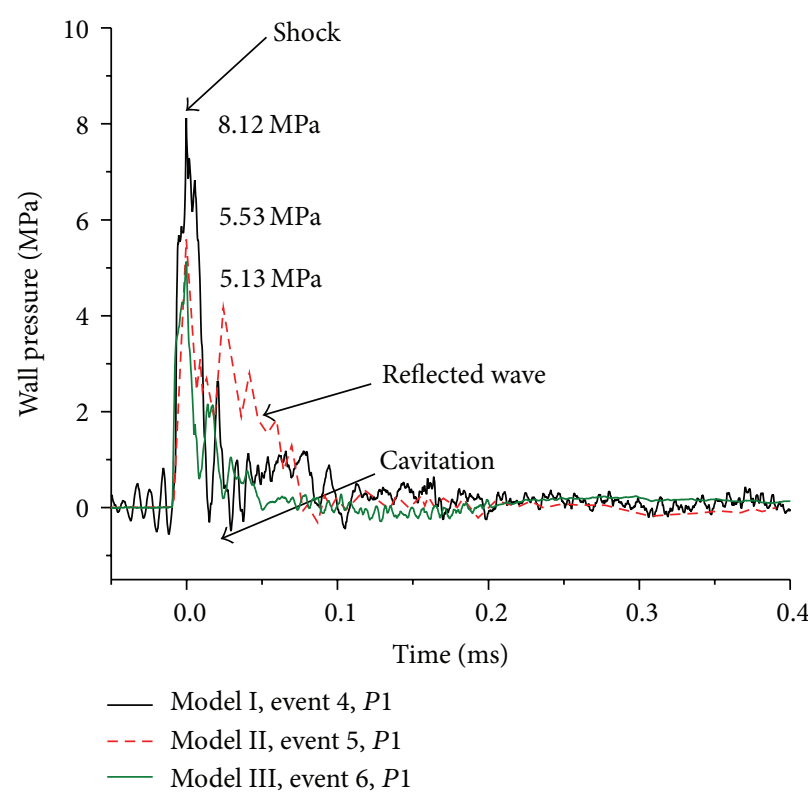

(a)

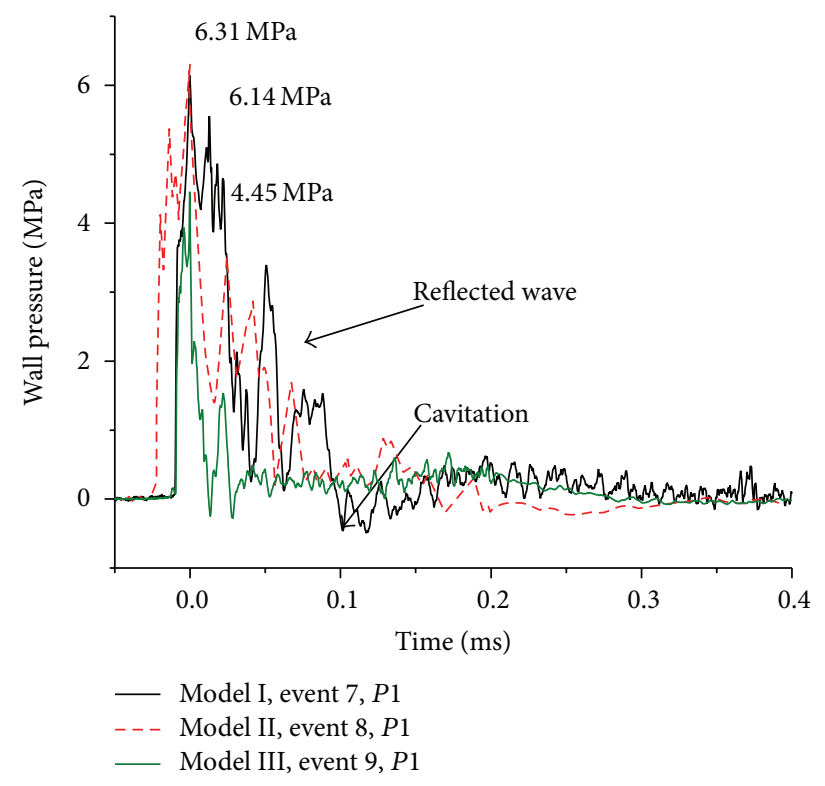

(b)

FIGURE 9: Comparison of the wall pressure-time histories: (a) $2.83 \mathrm{~m}$ stand-off, (b) $7.5 \mathrm{~m}$ stand-off.

Moreover, its reflected wave peak is larger and the pulse duration is longer than that of the other two. The reflected signals of model III are much fewer. The negative pressure of model I takes place early because the face sheet moves fast under the incident shock wave with a high pressure peak, but its duration is short. In Figure 9(b), the prominent discrepancies of the wall pressure waveform can be observed. The first incident wave peak of model III significantly decreases. The reflected wave peak of model I is the largest and its duration is very long. The reflected wave of model II is still obvious while the reflected signals of model III are faded. This is mainly due to the lower reflection characteristic of honeycomb coating. Another difference is that the cavitation for model III takes place much earlier than the other two, which results in a much narrower time span of the first incident shock wave. This should be attributed to the soft coating, which deforms much easier and faster when the shock wave impinges the face sheet.

The impulse transmitted to main structure is considered as the primary parameter that will determine the response. We compare the total impulse with the time span of $0.4 \mathrm{~ms}$ as listed in Table 4 . The impulse was calculated by the time integration of the wall pressure-time history. For $4.39 \mathrm{~m}$ standoff, the impulses of model II and model III are, respectively, reduced by $49 \%$ and $55 \%$ of the impulse of model I. For $2.83 \mathrm{~m}$ stand-off, the impulses of model II and model III are, respectively, reduced by $5 \%$ and $45 \%$. For $7.5 \mathrm{~m}$ stand-off, the impulses of model II and model III are, respectively, reduced by $8 \%$ and $60 \%$. The level of impulse reduction depends upon the time, the resistance to the motion of the front face sheet, and the cavitation after the shock reflection, which in turn is affected by the coating structure. As the front face is moving, a rarefaction wave is radiated back into the fluid
TABLE 4: Acceleration peaks unit (g).

\begin{tabular}{llccc}
\hline Event & $A 1$ & $A 4$ & $A 5$ & Average \\
\hline 1 & 624 & 436 & 1741 & 933 \\
2 & 443 & 394 & 1480 & 772 \\
3 & 182 & 266 & 360 & 269 \\
4 & 948 & 738 & 2672 & 1452 \\
5 & 762 & 655 & 2727 & 1381 \\
6 & 301 & 398 & 648 & 449 \\
7 & 945 & 795 & 3841 & 1860 \\
8 & 858 & 782 & 3433 & 1691 \\
9 & 335 & 426 & 731 & 497 \\
\hline
\end{tabular}

from the front face. The dispersion of the incident pressure is enabled by sequential crush of the coating. In addition, the acoustic mismatch between the water and the hull enhances the fluid-structure interaction effect. These factors result in an impulse reduction. The attenuation effect becomes outstanding because the reduction in impulse is facilitated by soft coating. As a result, lower structure responses induced by shock wave are anticipated in the subsequent sections.

\subsection{Acceleration Records}

3.2.1. Acceleration-Time Profiles. Figure 10 shows the detailed acceleration histories at location $A 5$. Despite some differences in these records, basic trends are consistent. An abrupt jump of signal indicates that the target responds to the arrival of shock wave and bubble pulse. Moreover, there exist fewer high frequency components in the coated models' records, which will be verified by later spectra analysis. It 


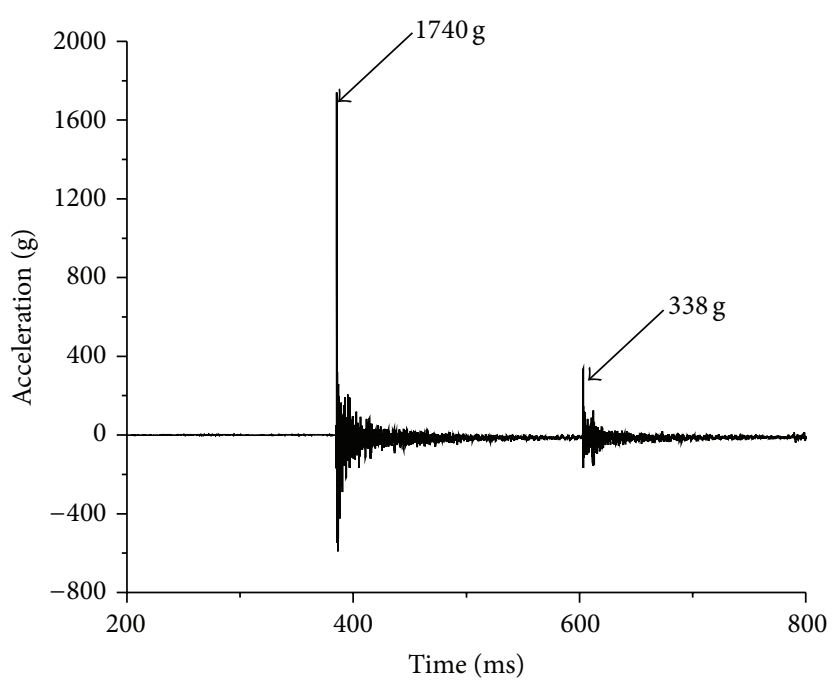

- Model I, event 1, A5

(a)

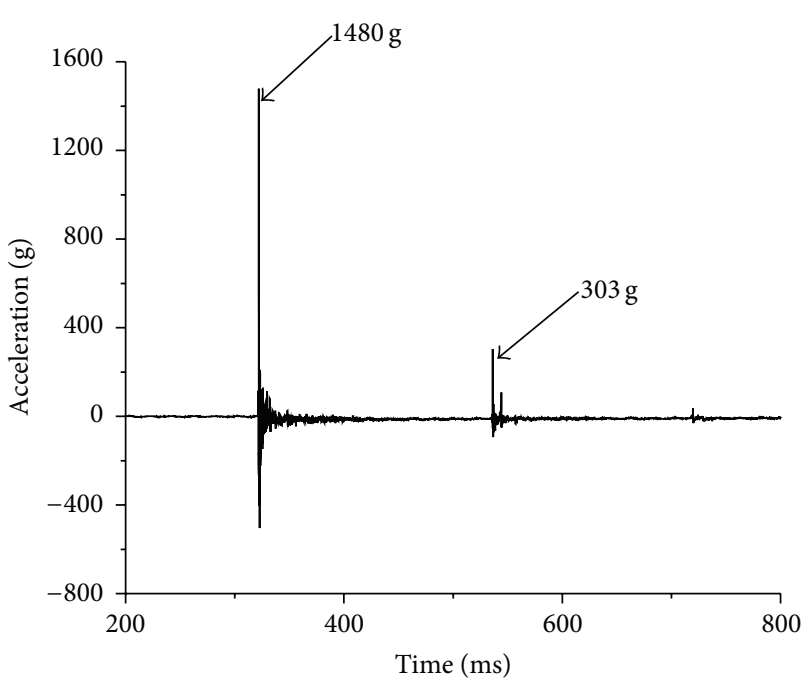

- Model II, event 2, A5

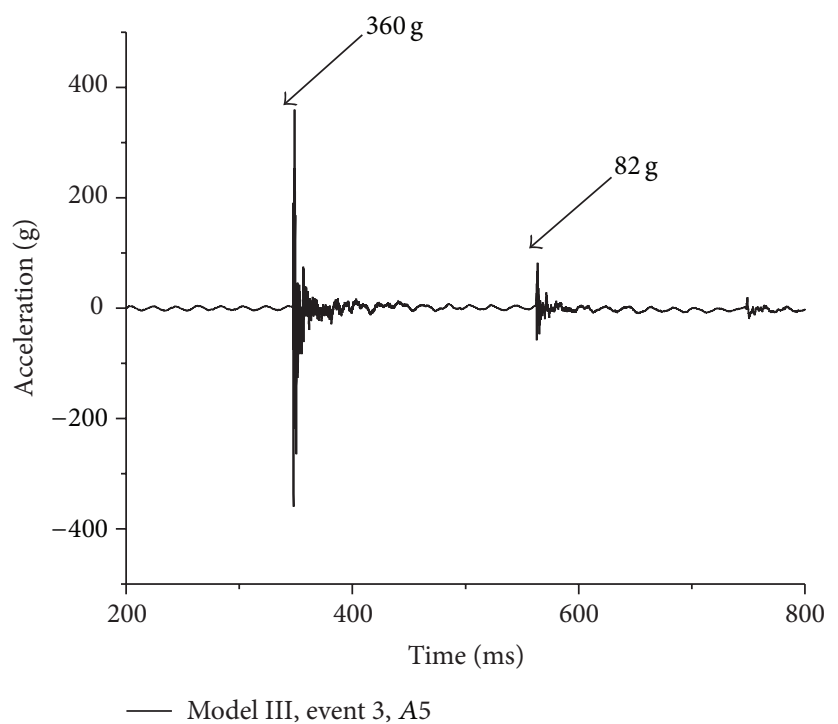

(b)

(c)

Figure 10: Acceleration histories at location A5: (a) event 1, (b) event 2, and (c) event 3.

is attributed to the high viscoelastic characteristics of the coatings. Acceleration peaks are compared to evaluate the protective effect. As expected, the peak induced by the shock wave is much larger than that induced by the bubble pulse. The maximum acceleration of model I for the shock wave and the first bubble pulse, respectively, reaches $1740 \mathrm{~g}$ and $338 \mathrm{~g}$. The maximum acceleration of model II for the shock wave and the first bubble pulse, respectively, reaches $1480 \mathrm{~g}$ and $303 \mathrm{~g}$. The maximum acceleration of model III for the shock wave and the first bubble pulse, respectively, reaches $360 \mathrm{~g}$ and $82 \mathrm{~g}$. The initial acceleration peak is reduced drastically after the coating is covered. The maximum response to the shock wave decreased from $1741 \mathrm{~g}$ to $360 \mathrm{~g}$, and the maximum response to the bubble pulse decreased from $338 \mathrm{~g}$ to $82 \mathrm{~g}$.
Honeycomb coating has a potential advantage due to the possibility of controlling the transferred force.

As a general comparison, Table 4 summarizes all the measured acceleration peaks in the shock wave phase. As the secondary shock waves have much smaller peaks and are usually much less damaging than the primary shock wave, the peaks caused by the bubble pulse are not given. Furthermore, the average peak of three test locations ( $A 1, A 4$, and $A 5$ ) corresponding to each event is presented. For $4.39 \mathrm{~m}$ stand-off, the average peaks of model II and model III are, respectively, reduced by $17.2 \%$ and $71.1 \%$ of the average peak of model I. For $2.83 \mathrm{~m}$ stand-off, the average peaks of model II and model III are, respectively, reduced by $4.9 \%$ and $69 \%$. For $7.5 \mathrm{~m}$ stand-off, the average peaks of model II and model 


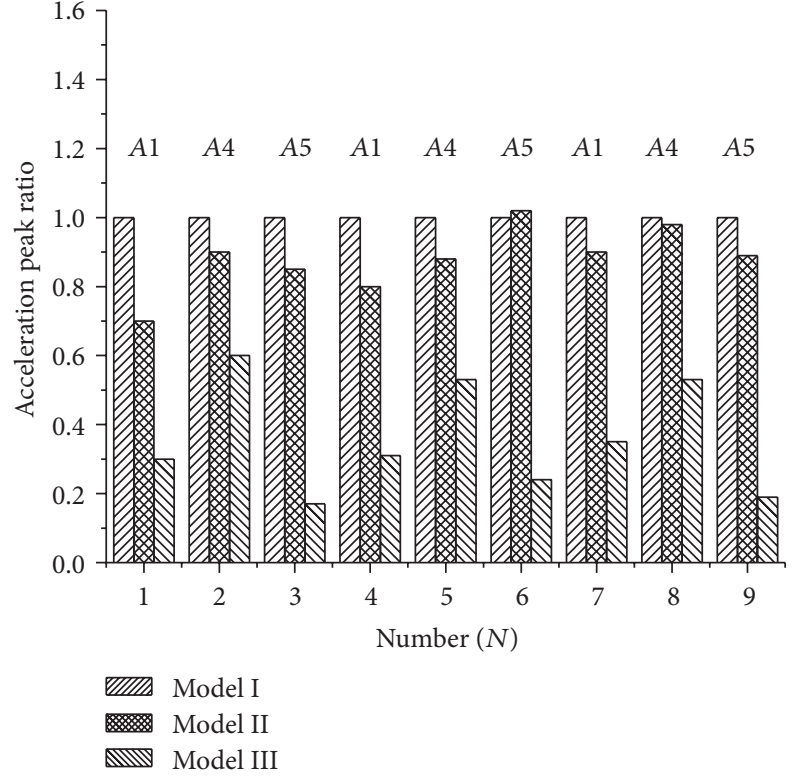

FIgURE 11: Acceleration peak ratio.

III are, respectively, reduced by $9.1 \%$ and $73.2 \%$. Prominent attenuation effects of model III are revealed. It can also be seen that the attenuation effect is related to coating as well as stand-off. When the stand-off equals $4.39 \mathrm{~m}$, the attenuation effect is significant.

To evaluate the attenuation effect conveniently, the acceleration peak ratio is defined between coated model and uncoated model. If it is less than unity, the acceleration is reduced and vice versa. Figure 11 shows the acceleration peak ratio. The stand-off of number $1 \sim$ number 3 is $4.39 \mathrm{~m}$. The stand-off of number $4 \sim$ number 6 is $2.83 \mathrm{~m}$. The stand-off of number $7 \sim$ number 9 is $7.5 \mathrm{~m}$. It can be seen that nearly all the peaks decrease after the coating is covered, and only one peak ratio (number 6) increases to 1.02 . This fact indicates that the attenuation effects of the coatings are global in nature. When the stand-off equals $4.39 \mathrm{~m}$, the maximum acceleration isolation of these coatings appears. The peak ratio of model II at location $A 1$ decreases to 0.7 (number 1) and 30\% of the acceleration of model $\mathrm{I}$ is cut off. The ratio of model III at location $A 5$ decreases to 0.17 (number 3 ) and $83 \%$ of the acceleration of model $\mathrm{I}$ is cut off. From the minimum acceleration isolation, the ratio of model III at $A 4$ decreases to 0.6 (number 2) and at least $40 \%$ of the acceleration of model I can be cut off.

In general, the attenuation effect of model III is much better than that of model II. The shock environment can be effectively improved by honeycomb coating. On one hand, due to the impedance mismatch, most of the incident shock energy is isolated by the coating. Meanwhile, when stress wave is transmitted from "hard" material into "soft" material, it will be reflected and turn into tensile wave, resulting in the wave decaying. On the other hand, as honeycomb cell walls provide structural support and regulate the stress to the back plate, they will deform and collapse sequentially when the coating is impinged by water blast wave. The cavities, like

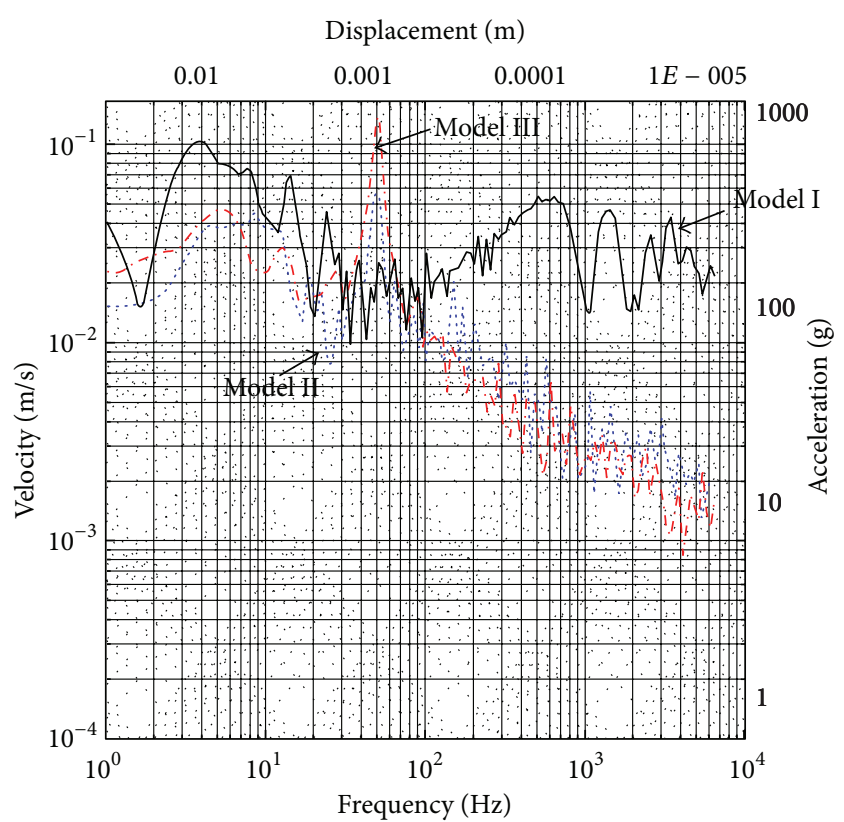

FIGURE 12: Shock response spectrums of three models (7.5 $\mathrm{m}$ standoff, $A 5$ test point).

closed air chambers, can provide adequate space for the large deformation of cell walls and desired blast mitigation. The results show that the structure with low impedance and high energy absorption capacity should be used as the protective layer.

3.2.2. Shock Response Spectrum. Shock response spectrum (SRS) is an effective method in understanding the frequency component of dynamic response of the structure subjected to shock input [3]. By comparing SRS curves of uncoated model and coated model, the influence of the coating on the transient response of the model can be partly revealed. As a comparison, the shock response spectrum from acceleration history of three models at location $A 5$ ( $7.5 \mathrm{~m}$ stand-off) is plotted in Figure 12. A5 test point is selected because the shock intensity is the highest and more structural modes can be excited. In spite of some differences between the SRS curves derived from different locations, common trend is similar. So other accelerometers are not presented. The analysis frequency band is between $1 \mathrm{~Hz}$ and $10 \mathrm{kHz}$.

It can be seen that in the frequency range lower than $30 \mathrm{~Hz}$ and higher than $100 \mathrm{~Hz}$, there is a distinct reduction of SRS value after the coatings are covered. The higher the frequency is, the more obvious the attenuation effect is. The protective effect of model III in high frequency range is better than that in low frequency range. At high frequencies, the spectrum curve is mainly controlled by local structural deformation and the energy decays rapidly as the damping effect predominates. Considering the zero drift of accelerometers, the response below $2 \mathrm{~Hz}$ is untrustworthy. The difference between two coated models at low frequencies is small, and the effect of model II is slightly better than that of model II. Comparing with high frequency range, the frequency 


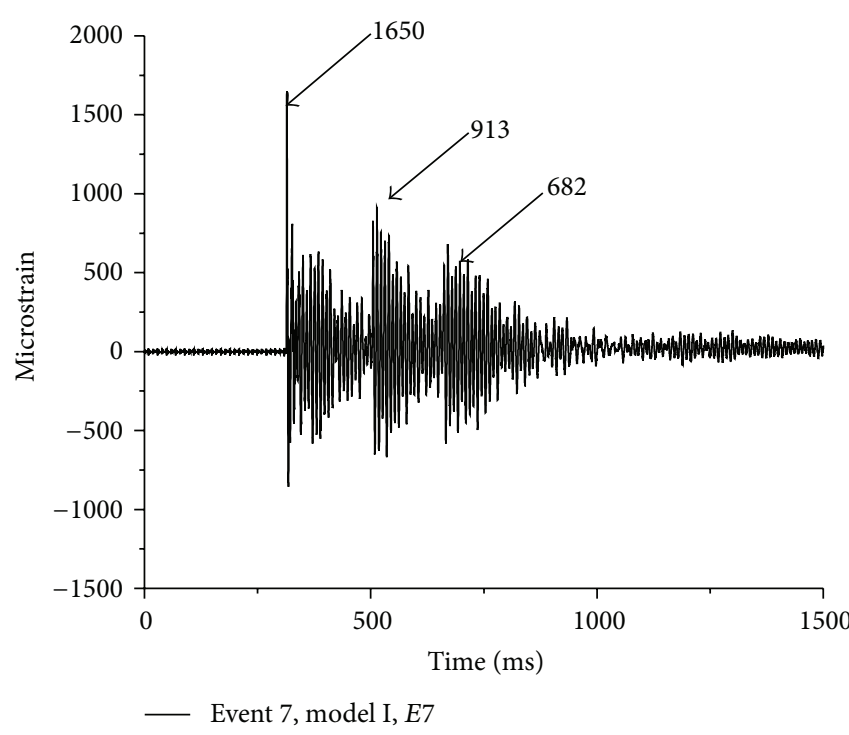

(a)

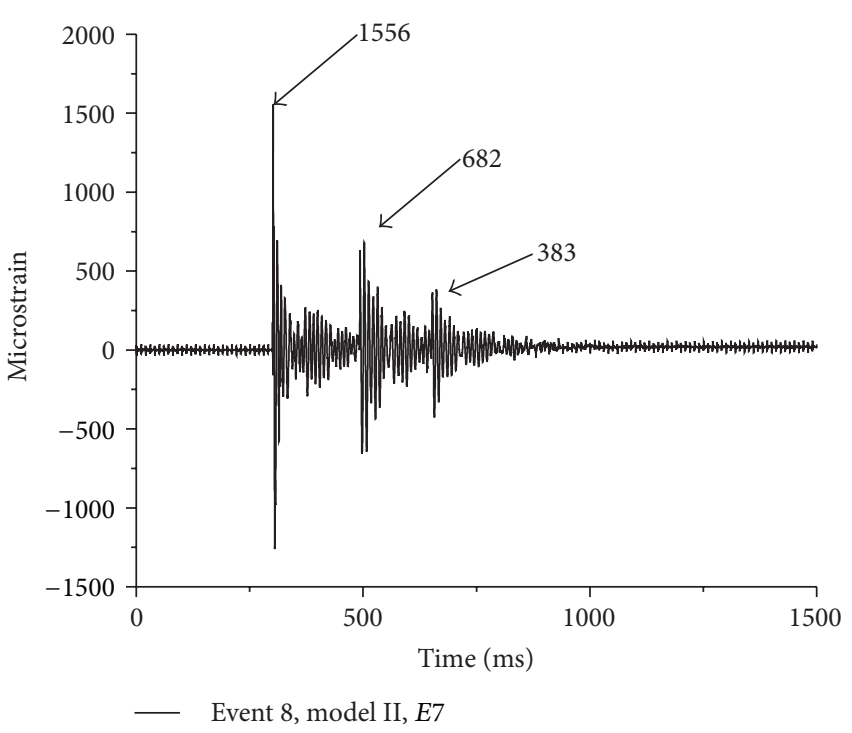

(b)

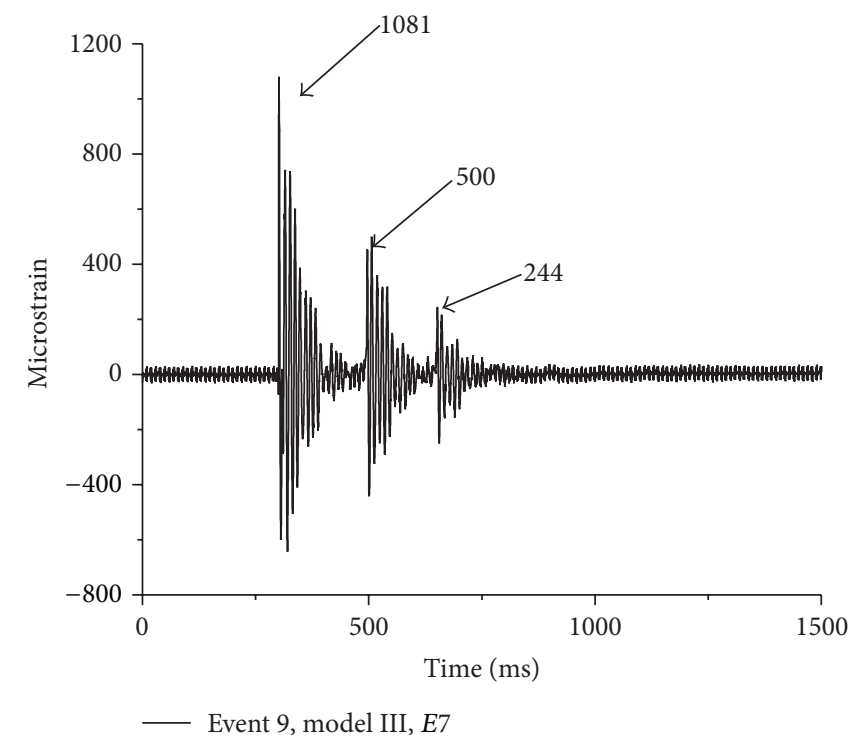

(c)

FIGURE 13: Strain histories at location E7: (a) event 7, (b) event 8, and (c) event 9.

band between $30 \mathrm{~Hz}$ and $80 \mathrm{~Hz}$ is the magnification region. Prominent peaks can be observed, which correspond to the global bending. The effects of coated models seem limited. Moreover, the response of model III is larger than that of model II.

3.3. Strain Records. Figure 13 shows the detailed strain histories with $1500 \mathrm{~ms}$ at E7. Like acceleration records, the strain responses to both shock wave and several bubble pulses can be distinguished. The maximum strain response to the bubble pulse is much smaller than that to the shock wave. The strain peaks of coated models are attenuated, especially for the shock wave. High frequency signal decays and vibration dominates at low frequency. Owing to the high damping of the coatings, there exist fewer high frequency components for coated models.

Table 5 lists all the measured strain peaks in the shock wave phase. Only tensile strain is considered, which is often selected as a failure criterion of ductility. It is difficult to evaluate the actual attention effect of the coating from only a few points, so we have to make an evaluation by a statistic method. The average strain except $E 4$ corresponding to each event is listed in Table 4 . For $4.39 \mathrm{~m}$ stand-off, the average peak ratios of model II and model III, respectively, decrease to 0.79 and 0.68 of the average peak of model I. For $2.83 \mathrm{~m}$ standoff, the peak ratios of model II and model III, respectively, decrease to 0.87 and 0.77 . For $7.5 \mathrm{~m}$ stand-off, the peak ratios of model II and model III are, respectively, closed to 1 and 0.76 . Like acceleration records, when the stand-off is $4.39 \mathrm{~m}$, 


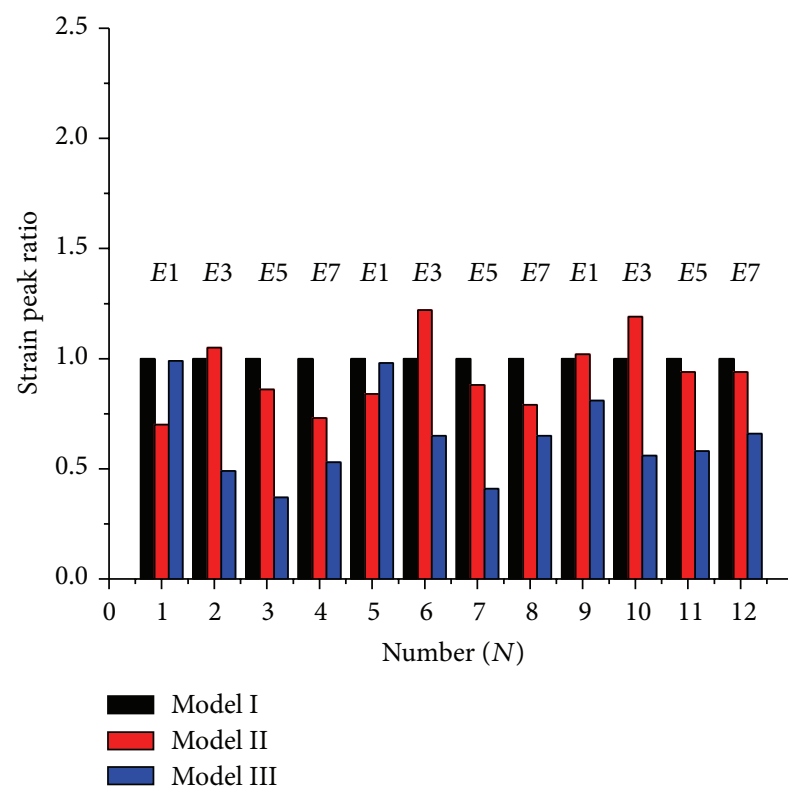

(a)

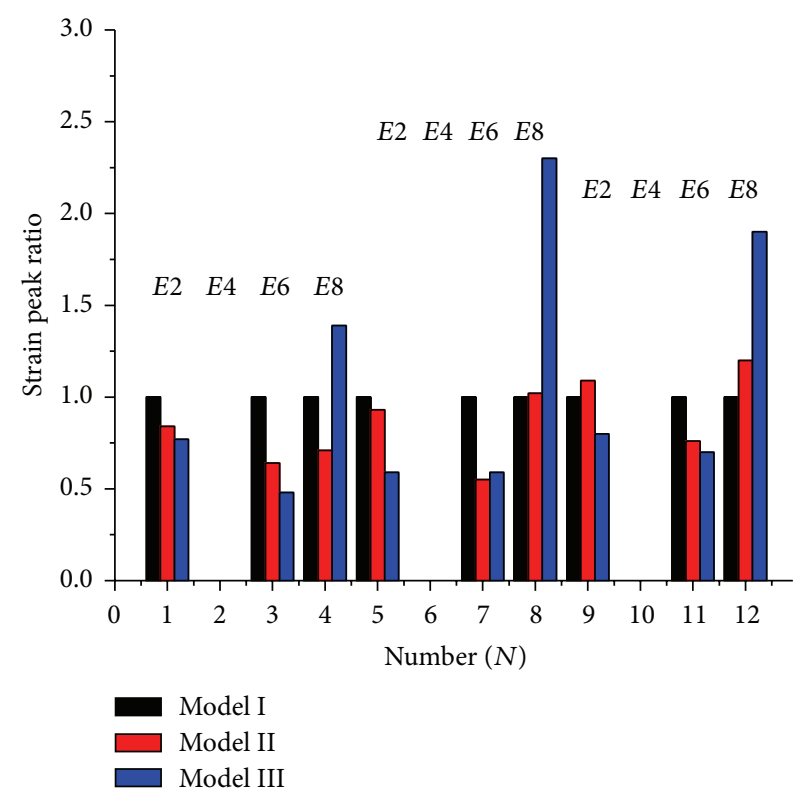

(b)

FIGURE 14: Strain peak ratio: (a) transverse direction, (b) longitudinal direction.

TABLE 5: Strain peaks $(\mu \varepsilon)$.

\begin{tabular}{lccccccccc}
\hline Event & $E 1$ & $E 2$ & $E 3$ & $E 4$ & $E 5$ & $E 6$ & E7 & E8 & Average (except E4) \\
\hline 1 & 844 & 666 & 752 & - & 970 & 718 & 887 & 595 & 776 \\
2 & 598 & 563 & 789 & 545 & 835 & 457 & 646 & 424 & 616 \\
3 & 839 & 513 & 369 & 178 & 362 & 345 & 475 & 825 & 532 \\
4 & 985 & 861 & 1000 & - & 1472 & 1237 & 1261 & 622 & 1062 \\
5 & 829 & 807 & 1229 & 1155 & 1306 & 686 & 1005 & 636 & 928 \\
6 & 965 & 510 & 655 & 786 & 604 & 735 & 825 & 1434 & 818 \\
7 & 1086 & 787 & 1377 & - & 1602 & 1343 & 1650 & 682 & 1218 \\
8 & 1108 & 859 & 1647 & 1219 & 1512 & 1029 & 1556 & 840 & 1221 \\
9 & 884 & 633 & 773 & 892 & 926 & 936 & 1081 & 1315 & 935 \\
\hline
\end{tabular}

the average peak ratio of coated models is the minimum. The average strain of coated model decreases to some extent, except for event 8 . The peak ratios of model II range from 0.79 to 1 , and the ratios of model III range from 0.68 to 0.77 . The results prove that better overall strain attenuation can be obtained by the honeycomb coating.

Similarly, strain peak ratio is defined between coated model and uncoated model. Figure 14 shows the transverse ratio and longitudinal ratio. The stand-off of number 1 number 4 is $4.39 \mathrm{~m}$. The stand-off of number $5 \sim$ number 8 is $2.83 \mathrm{~m}$. The stand-off of number $9 \sim$ number 12 is $7.5 \mathrm{~m}$.

It can be seen that the strain attention effect is related to stand-off and test point. The large strain isolation of model II appears at E6 under three stand-offs. For $4.39 \mathrm{~m}$ stand-off, the large isolation of model III appears at E3 to E7. For $2.83 \mathrm{~m}$ stand-off, the large isolation of model III appears at E5 and E6. For $7.5 \mathrm{~m}$ stand-off, the large isolation of model III appears at E3 and E5.

After the coating is covered, the strain peaks at most of the test points decrease in some degree. The minimum peak ratio of model III is 0.37 corresponding to number 3 of Figure 14(a), and the minimum ratio of model II is 0.55 corresponding to number 7 of Figure 14(b). The maximum strain isolation of model III is larger than that of model II. However, the prominent strain enlargements of coated models at some test points are also presented. This fact indicates that no protective effects can be brought by coatings and the attenuation effects are restricted to local area. For model II, the strain enlargement exists in number 2, number 6 , number 9, and number 10 of Figure 14(a) and number 8, number 9, and number 12 of Figure 14(b). The peak ratios range from 1.02 to 1.22 . For model III, the strain enlargement exists in number 4 , number 8 , and number 12 of Figure 14(b). The peak ratios range from 1.39 to 2.39. Furthermore, in number 1 and number 5 of Figure 14(a) and number 4, number 7 , number 8 , and number 12 of Figure 14(b), model III sustains greater shock damage than model II under identical testing conditions. It indicates that the stress concentration is more evident for the coating with lower impedance. The strain can be manifested over two times at the most execrable 
locations. This should be attributed to the fact that the stress wave transmitted from water to steel shell via coating cannot be released outward timely for the impedance mismatch between hull and coating. Therefore, the shock energy is accumulated before it is dissipated by structural damping and the stress concentration takes place. As Kwon points out that, for the impedance mismatch between rubber and steel, when stress wave is transmitted into inner steel plate, the stress will concentrate when the impedance of rubber is lower than a certain limit. The softer elastic coating inhibits release of stress wave energy from the structure to the surrounding water. When stress wave is transmitted from "soft" material into "hard" material, the intensity of transmission wave will exceed that of incident wave. The excess energy is manifested in the form of higher stresses in the underlying structure. Therefore, a higher stress state accompanies a coating with smaller characteristic impedance. In addition, a noticeable phenomenon is that the strain of model II is manifested in both directions while the strain of model III only is manifested in the longitudinal direction. The discrepancy is due to the difference of wave length in two directions. Meanwhile, like the strain attention effect, the strain enlargement of the coating is related to stand-off and test point. When stand-off is $2.83 \mathrm{~m}$, the strain enlargements of two coated models are the maximum. There exist four strain enlargement points ( $E 1$, $E 2, E 3$, and $E 8$ ) for model II, while there is only one point (E8) for model III. When the test point is close to the explosive charge, its strain enlargement becomes evident.

In general, the strain on the outer hull in direct contact with the coating is often manifested. The amplification factor should be related to stress wave type and direction as well as other factors such as the wave impedance mismatch between structure and coating. Results show that the stress concentration is a very complicated nonlinear phenomenon and affected by almost all kinds of factors in the whole underwater explosion process. Softer coating with low acoustic impedance generally tends to concentrate the stress wave energy in the hull. The stress concentration induced by the impedance mismatch cannot be neglected. Such a response may entail increased strains and internal energy causing plastic deformation and failure of the structure.

\section{Conclusion}

This paper experimentally investigated the water blast attenuation effect and dynamic response of a free floating stiffened box with rubber coatings covered onto the bottom hull subjected to UNDEX. The comparison of wall pressure histories indicates that attenuation effects primarily originate from the fact that the coatings can substantially reduce the incident impulse at the initial fluid-structure interaction stage, which is very beneficial for the protection of underwater structures. The attenuation effect of honeycomb coating is significantly enhanced by local cavitation. The acceleration responses of inner structures to both shock wave and bubble pulse can be greatly lowered, especially for the shock wave. The relative benefit of honeycomb coating is significantly enhanced over its solid counterpart under the same shock condition. Rubber coatings provide additional damping for reducing high frequency response of the structure. Strain results have exhibited two types of effects. Due to the impedance mismatch between the interfaces of materials, stress concentration takes place mainly on the outer shell that directly contacts the coating. A softer rubber coating concentrates the stress wave within the structure, which contributes to increased stress magnitudes and induces a greater magnitude of strain. The strain enlargement is related to the coating structure, attack angle, stand-off, and location of strain recorded.

\section{Conflict of Interests}

The authors declare that there is no conflict of interests regarding the publication of this paper.

\section{Acknowledgments}

The authors would like to thank the China National Natural Science Funding for financially supporting this research under Grant no. 11272215. The authors would also like to thank the opening fund of State Key Laboratory of Mechanical System and Vibration.

\section{References}

[1] G. S. B. Roshdy, "Advanced ship protection and low signature hull," in Proceedings of the Navy Industry R\&D Partnership Conference, Washington, DC, USA, 2002.

[2] C. M. Harris and C. E. Crede, Shock and Vibration Handbook, McGraw-Hill, New York, NY, USA, 2002.

[3] R. J. Scavuzzo and H. C. Pusey, Naval Shock Analysis and Design, Shock and Vibration Information Analysis Center, Allen and Hamilton, Falls Church, Va, USA, 2000.

[4] Z. Xue and J. W. Hutchinson, "A comparative study of impulseresistant metal sandwich plates," International Journal of Impact Engineering, vol. 30, no. 10, pp. 1283-1305, 2004.

[5] G. J. McShane, D. D. Radford, V. S. Deshpande, and N. A. Fleck, "The response of clamped sandwich plates with lattice cores subjected to shock loading," European Journal of Mechanics A, vol. 25, no. 2, pp. 215-229, 2006.

[6] M. D. Theobald, G. S. Langdon, G. N. Nurick, S. Pillay, A. Heyns, and R. P. Merrett, "Large inelastic response of unbonded metallic foam and honeycomb core sandwich panels to blast loading," Composite Structures, vol. 92, no. 10, pp. 2465-2475, 2010.

[7] E. Wang, N. Gardner, and A. Shukla, "The blast resistance of sandwich composites with stepwise graded cores," International Journal of Solids and Structures, vol. 46, no. 18-19, pp. 3492-3502, 2009.

[8] N. A. Fleck and V. S. Deshpande, "The resistance of clamped sandwich beams to shock loading," Journal of Applied Mechanics, Transactions ASME, vol. 71, no. 3, pp. 386-401, 2004.

[9] Z. Xue and J. W. Hutchinson, "Preliminary assessment of sandwich plates subject to blast loads," International Journal of Mechanical Sciences, vol. 45, no. 4, pp. 687-705, 2003.

[10] K. Mäkinen, “The transverse response of sandwich panels to an underwater shock wave," Journal of Fluids and Structures, vol. 13 , no. 5, pp. 631-646, 1999. 
[11] V. S. Deshpande and N. A. Fleck, "One-dimensional response of sandwich plates to underwater shock loading," Journal of the Mechanics and Physics of Solids, vol. 53, no. 11, pp. 2347-2383, 2005.

[12] L. M. Yueming, A. V. Spuskanyuk, S. E. Flores et al., "The response of metallic sandwich panels to water blast," Journal of Applied Mechanics, Transactions ASME, vol. 74, no. 1, pp. 81-99, 2007.

[13] C. H. Kim and Y. S. Shin, "Numerical simulation of surface shield effects to water blast wave," Ocean Engineering, vol. 60, pp. 99-114, 2013.

[14] Y. Chen, Z. P. Tong, H. X. Hua, Y. Wang, and H. Y. Gou, "Experimental investigation on the dynamic response of scaled ship model with rubber sandwich coatings subjected to underwater explosion," International Journal of Impact Engineering, vol. 36, no. 2, pp. 318-328, 2009.

[15] Y. Chen, Z. Zhang, Y. Wang, H. Hua, and H. Gou, "Attenuating performance of a polymer layer coated onto floating structures subjected to water blasts," European Journal of Mechanics A, vol. 28, no. 3, pp. 591-598, 2009.

[16] Y. E. Kwon, J. K. Bergersen, and Y. S. Shin, "Effect of surface coatings on cylinders subjected to underwater shock," Shock and Vibration, vol. 1, pp. 253-265, 1994.

[17] T. P. Brasek, Effect of surface coatings on one-dimensional system subjected to unit step pressure wave [M.S. thesis], Naval Postgraduate School, Monterey, Calif, USA, 1994.

[18] Y. Chen, Y. Wang, Z. Zhang, and H. Hua, "Experimental research on the responses of neoprene coated cylinder subjected to underwater explosions," Journal of Offshore Mechanics and Arctic Engineering, vol. 135, no. 1, Article ID 011102, 2013.

[19] S. W. Gong and K. Y. Lam, "On attenuation of floating structure response to underwater shock," International Journal of Impact Engineering, vol. 32, no. 11, pp. 1857-1877, 2006.

[20] L. A. Louca, Y. G. Pan, and J. E. Harding, "Response of stiffened and unstiffened plates subjected to blast loading," Engineering Structures, vol. 20, no. 12, pp. 1079-1086, 1998.

[21] Y. Chen, Z. Zhang, Y. Wang, and H. Hua, "Crush dynamics of square honeycomb thin rubber wall," Thin-Walled Structures, vol. 47, no. 12, pp. 1447-1456, 2009.

[22] Y. Wang, Underwater Explosion Impact Test and Protection Technology of Ship, National Defence Industry Press, Beijing, China, 2010.

[23] R. H. Cole, Underwater Explosions, Princeton University Press, Princeton, NJ, USA, 1948. 

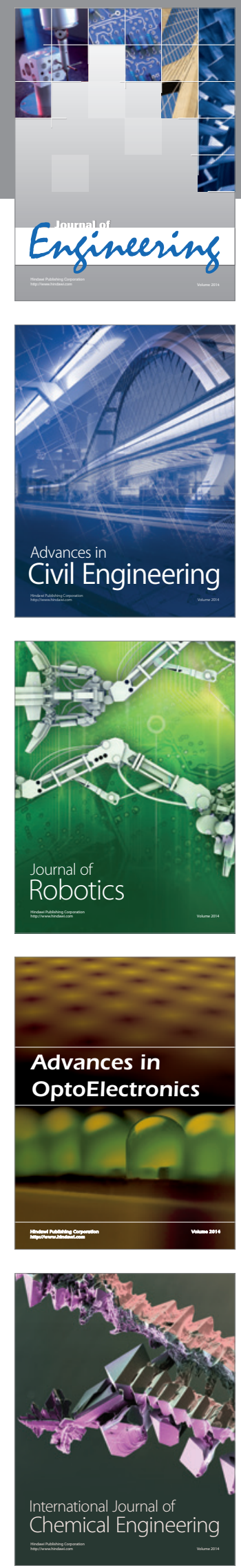

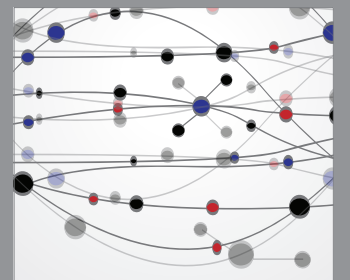

The Scientific World Journal
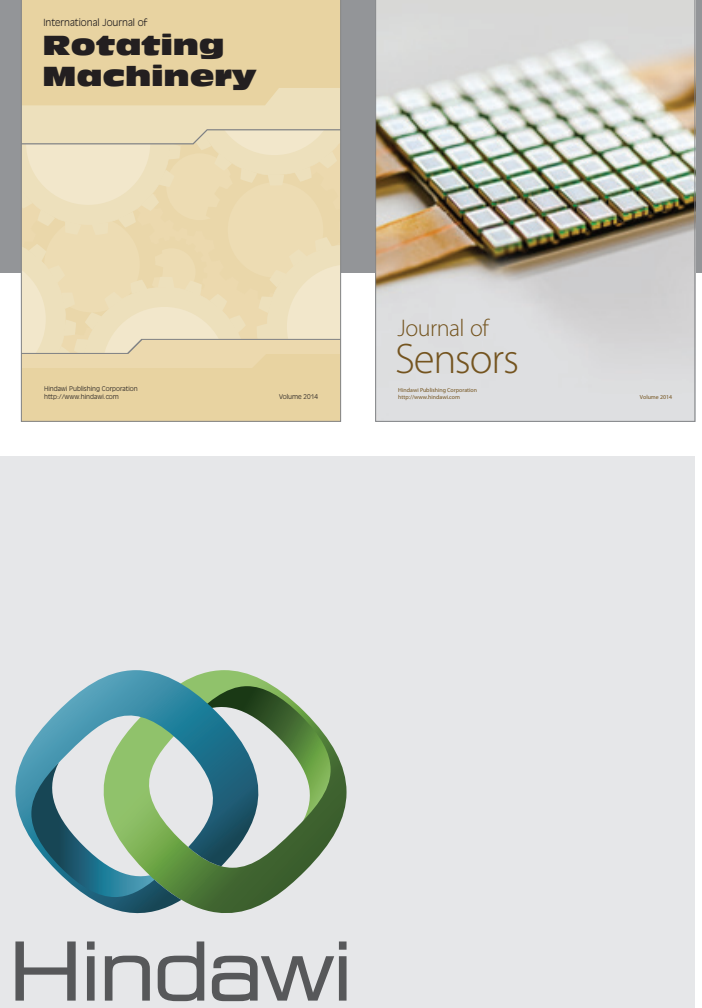

Submit your manuscripts at http://www.hindawi.com
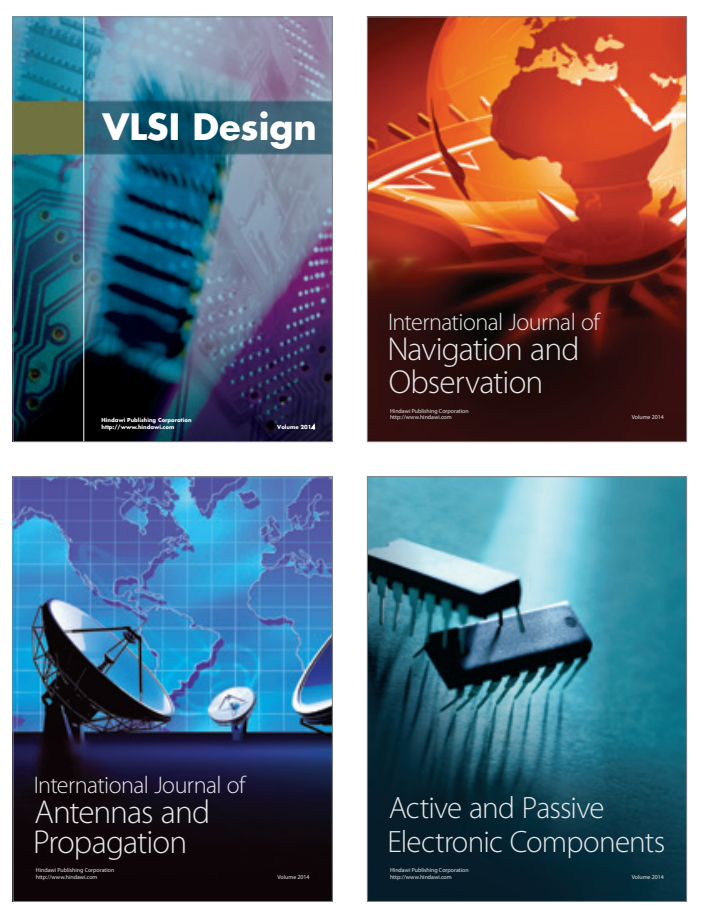
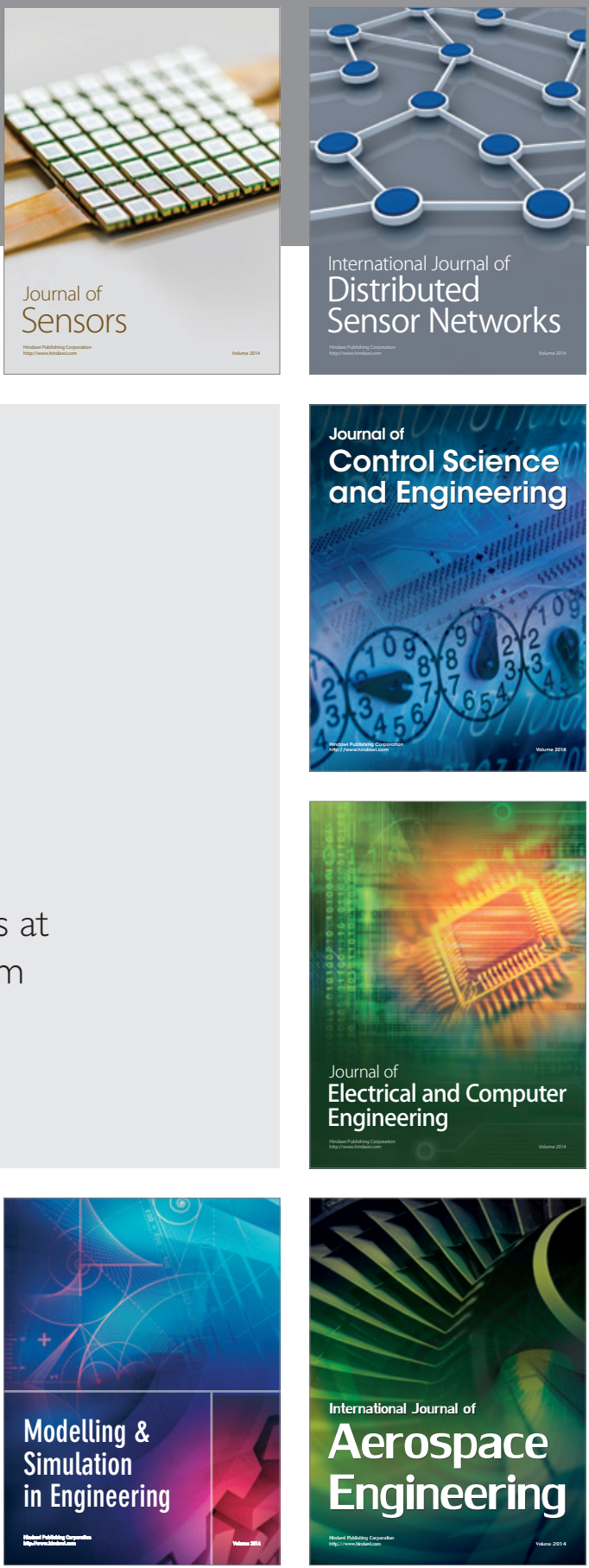

Journal of

Control Science

and Engineering
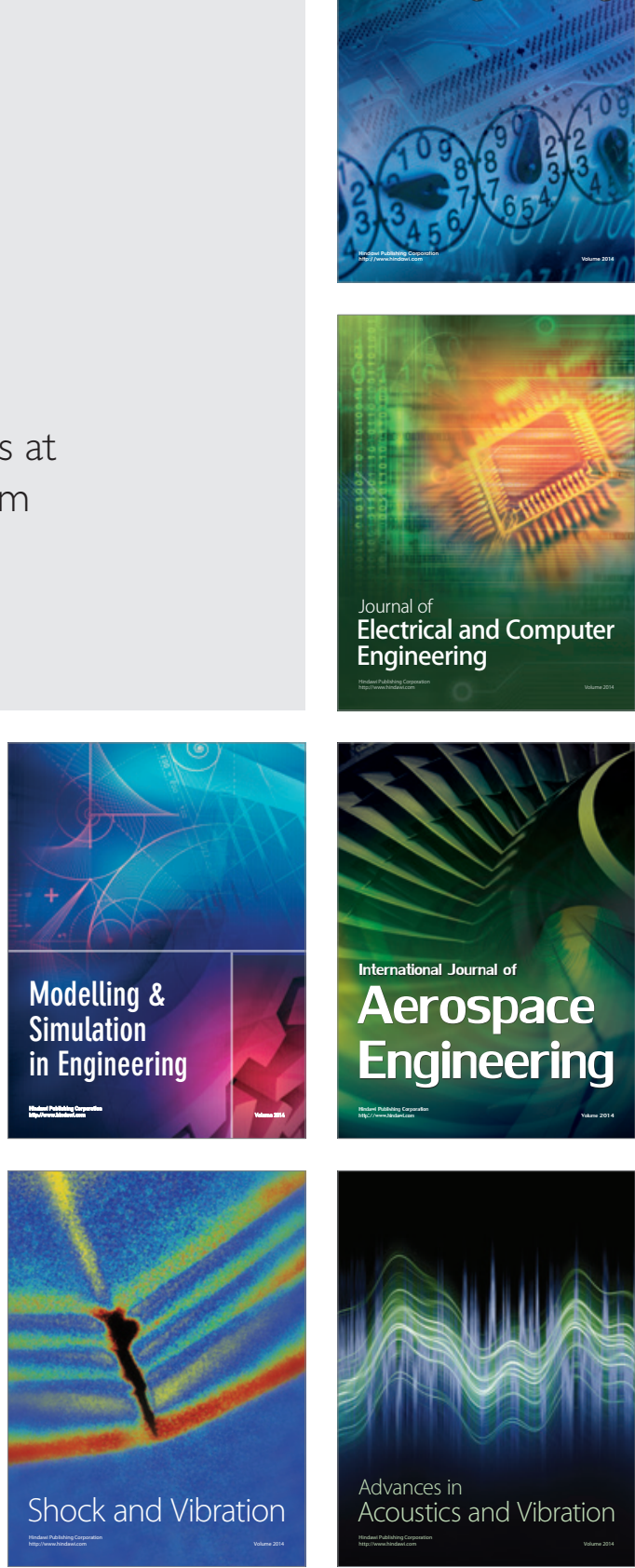